Course of Disease.-I was inclined to regnrd the case as one of neurasthenia, exaceroated by auto-intoxication, and prescribed calomel in repeated doses during the day and salts in the morning. The next day the vomiting had ceased and the headache was better, but the speech was worse; the patient was subject to attacks of mental excitement. I advised his removal to hospital. He got up and dressed but I noticed that, although he put his tie-pin in straight, he was quite unable, after several minutes of effort, to adjust the fastener to its point. Romberg's sign was still absent. As he walked to the elevator money fell from his pocket but its loss was unnoticed. He chatted merrily on the way and walked up the hospital steps without effort. Vomiting was absent all that day and headache was slight. Temperature on admission, 97.6 ; pulse 70 ; calomel continued, $1 / 8$ grain every two hours.

June 12: Patient had severe headache and sleeplessness during the night, but at 7 a. $m$. seemed much improved, spoke much more distinctly and grasped ideas better. Temperature 99, pulse 50, respirations 18 .

This day a barely detectable weakness of the right arm and a trifling exaggeration of the tendon-jerks and epigastric reflex on the right side was present. The right plantar reflex was still flexor, but the great toe did not go down so briskly or so far as did the great toe on the left side; the second and third toes on the right side went up, but all the left toes went down. The face, upper and lower, moved equally to voluntary and emotional effort. In the absence of any apparent cause for cerebral abscess and the freedom from vomiting, from optic neuritis and from abducent weakness I regarded the case at this time as one of cerebral thrombosis. The presence of gastritis was sufficient to account for the low fever.

June 12: Potassium iodid administration begun and icecap applied. Patient complained of some sore throat.

June 13 to June 16: Little change. More or less headache with remissions present. Temperature range, from 98.6 morning, to 99.6 evening. Pulse, 54 to 84, with average of 60 . Aphasia decidedly more marked.

June 16, morning: The patient looks and feels better. Right arm is used freely, but when at rest the hand is held in the classic hemiplegic position.

June 17: Marked hebetude. Pain localized on left side of head. Examination of the optic disks at my request by $\mathrm{Dr}$. Frank Miller confirmed a beginning neuritis at the nasal side of each disk.

Operation.-June 17, I turned down an osteoplastic flap, the center of which corresponded to the angular gyrus. The dura bulged slightly and did not pulsate, the cortex was darker than normal and the vessels swollen. A trocar was inserted with a negative result. Exploration deep toward the lenticular nucleus with the little finger disclosed a cavity about the size of a small walnut, which was filled with thick ill-smelling pus. After this was evacuated, another smaller cavity was opened up as the drainage-tube was inserted. The tube was left in situ and brought through the center of the osteoplastic flap.

Postoperative History.-June 18, there was pronounced right hemiplegia, the face being only slightly affected.

June 20 , the paralysis began to improve, as well as the mental condition and speech, but the drainage was slight from the first.

From June 22 the patient became more comatose and more toxic. June 24, I removed the bone flap and explored the abscess cavities, which were in a satisfactory condition and the meninges were well shut off. On the thirteenth day following the opcration, however, the patient gradually sank and died.

Post-Mortem Findings: No meningitis existed beyond the field of operation. There were two abscess cavities side by side in the white matter of the angular and intraparietal lobes, each rather larger than half a walnut. The anterior one led by a narrow channel to a recent abscess the size of a hazelnut in the left optic thalamus. The other abseess cavity was separated from the left lateral ventricle by a narrow velum only.
The abscess in the optic thalamus presumably caused death. No sign of ear or nose disease was present. The organisms in the pus were declared by $\mathrm{Dr}$. C. W. Bonynge of Los Angeles to be Pfeiffer's bacillus of influenza and Staphylococcus aureus.

This case to my mind indicates the importance of early exploratory operation in doubtful cases of intracranial disease. I should not have waited for indications of optic neuritis and, although the diagnosis of thrombosis with cerebral softening was justifiable in the absence of any probable cause of abscess, nevertheless a well-executed decompression and inspection of the area indicated by the focal signs can do no great harm in thrombosis, and if in this case it had been performed June 11 , instead of June 17 , the ultimate result would, I think, have been different.

A similar case is reported by Dr. J. Henderson. ${ }^{2}$ The abseess in this case was in exactly the same situation and on the left side but it burst into the ventricle. Dr. Henderson in his report says in conclusion that in such cases with no evidence of the origin of the infection a diagnosis of abscess must always be uncertain.

\section{A CASE OF HARDWARE SWALLOWING}

\section{W. O. Wilder, M.D., Pitrsfield, Mass.}

History.-L. P., aged 41 , a carpenter since 16 , admitted to the House of Mercy Hospital, Oct. 24, 1912, juggled coins in his mouth and throat, when a youth, for the amusement of his

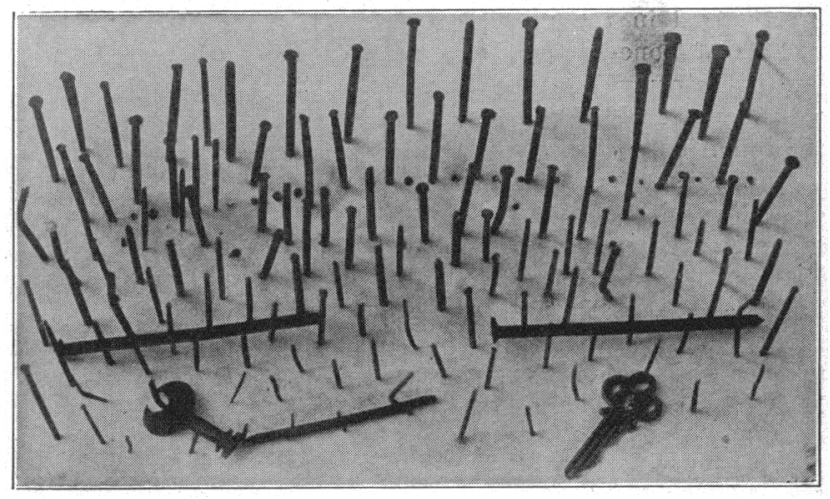

Foreign bodics removed from the stomach.

friends. In 1908 he began to swallow nails for money, and later indulged in a diet of knives, cigars, etc., which he would vomit up sometimes and at other times pass by bowel. He said that he was accustomed to swallow 4 feet of 1 -inch dog-chain, and women's neck-chains of similar length. These were usually redrawn from the stomach. For the past four or five years the patient has suffered with sharp pains in the abdomen, which were partially relieved by partaking of food. The pains recently had become extremely acute and constant, being localized in the left upper quadrant of the abdomen, and made nore severe by any movement of the body.

Examination.-The bowels were regular and the stools contained no blood. The patient was very much emaciated. The lungs and heart were negative, the abdomen flat and rigid. Pressure demonstrated no tumor but did elicit an extremely tender area in the left upper quadrant. Roentgenoscopy revealed a definite irregular-shaped shadow in the left upper quadrant of the abdomen.

Operation.-An incision was made in the left rectus above the umbilicus. An adhesion of stomach to the abdominal wall was freed and a small perforation of stomach was found through which protruded the point of a nail. After the field of operation had been thoroughly walled off with gauze, the perforation was so enlarged as to admit the hand, and two keys, two twelvepenny nails and 130 other nails and pieces

1. Henderson, John: A Case of "Idiopatbic" Cerellal Abscess, Laricet, London, May 31, 1913 , p. 1525. 
of wire were removed. These foreign bodies lay in a pouchshaped distention of the cardiac end of the stomach and weighed $3 / 4$ of a pound in bulk.

Recovery was uneventful.

\section{A TRANSVERSE INCISION FOR OPERATION ON THE SCROTUM}

George Morris Corrance, M.D., Philladelphia Surgeon to St. Agnes' Hospital

In operations on the scrotum, the longitudinal incision is the one described in all the text-books which I have consulted. On examination of the lower half of the scrotum,

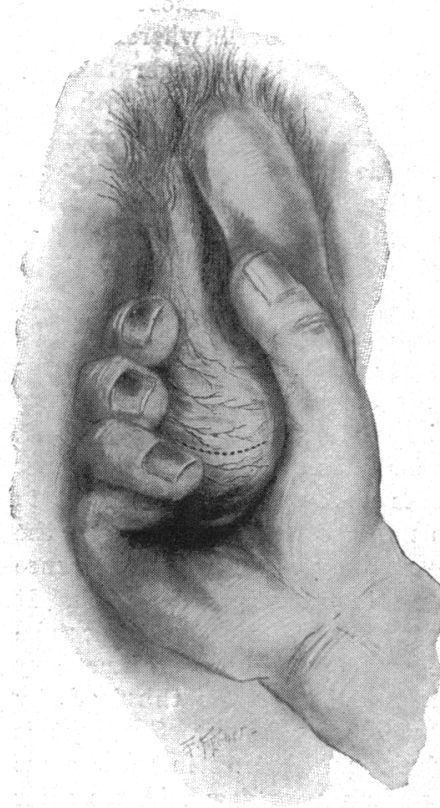

Transverse incision (indicated by the dotted line) between superficial vessels of scrotum. the longitudinal incision transversely. The longitudinal incision does not produce a neat wound. The dotted line indicates the line of incision.

2025 Walnut Street.

A Case of Right Inguinal Hernia of Ovary and TubeL. P., student, aged 12, was brought to the office in October, 1913 , by her parents because of a right inguinal hernia. Her parents could not remember when the trouble was first noticed, but said that other physicians had told them that the child was ruptured and preseribed a truss which she had worn for some years. Except for the inconvenience of wearing the truss, the hernia troubled her very little. At this time there was nothing in the inguinal canal and the hernia had always been easily reduced. On December 15 I was called to the house to see the patient. Two days before, while not wearing her truss, she coughed and a swelling appeared in the right inguinal region, which she was unable to reduce. On examination a small, oval, tender mass the size of an almond was found in the right inguinal canal. This could be moved a certain distance up and down the canal but could not be replaned in the abdominal cavity. A probable diagnosis of hernia of the ovary was made and the child sent to the hospital. At the operation the sac was found to contain the right ovary and tube but no bowel or omentum. The ovary and tube were replaced in the abdominal cavity and the wound closed in layers in the usual way. The subsequent history is of no interest.-ALbert S. BARR, M.D., Greenville, Mich.

\section{A CONGENITAL MALFORMATION OF THE NECK}

Charles A. Parker, M.D., Chicago

In May, 1912, the patient, A. F., a girl aged about 11, came to the service of Drs. Blanchard and Parker at the Home for Destitute Crippled Children, for the correction of a peculiar deformity involving principally the skin on both sides of the neck. The deformity is well illustrated in Figure 1 , and consisted of two symmetrical wing-like folds of skin extending from either mastoid region to the top of the shoulder. These wings had always existed to some extent and changed very little in appearance with muscular contraction. They interfered somewhat with the movements of the head, but it was more on account of the deformity that their removal was sought. The redundant fold of skin was removed by an incision extending from the mastoid to the outer end of the clavicle on either side of the fold leaving an elliptical wound which, when closed, made a more nearly normal-appearing neck (Fig. 2). On account of troublesome anesthesia the two folds were removed at separate operations. The portion removed, besides the skin, contained fibrous tissue in which were included some muscle fibers. No microscopic examination was made. The position of the fold, just behind the ear, was too far forward for the trapezius, and the bottom was too far out on the shoulder for the sternomastoid.

The case is unique as far as our knowledge and experience go and we can offer no plausible explanation of its development. The family history, however, suggests a very definite

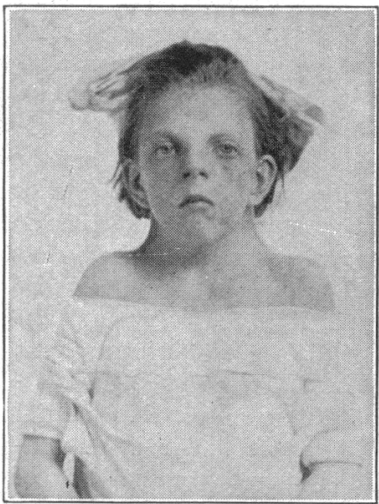

Fig. 1.-Congenital malformation of the neck.

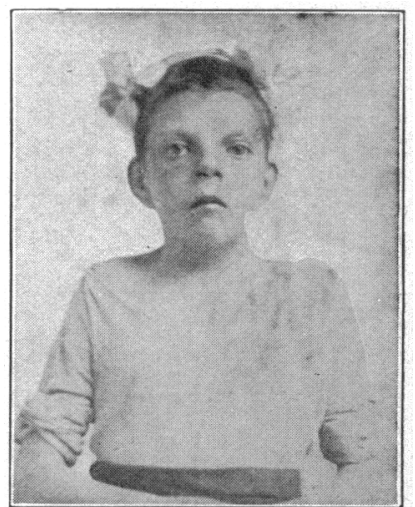

Fig. 2.-Patient in Figure 1 after operation. factor in its origin. The father has locomotor ataxia, an older sister has a congenital dislocation of the hip and five children died during infancy, one being still-born.

The accompanying illustrations show the facial characteristics of this child. Later she developed a dislocation of the patella, resembling the congenital type, which was cured by operation.

7 West Madison Street.

Morbidity Statistics in the United States.-We must not let ourselves be blinded by statistics, for the statistics of disease in the United States are notoriously unreliable. For certain sections no attempt whatever is made to collect them.

* * * Until severe penalties are inflicted for failure to report cases of infectious diseases, until failure to do so results in the cancellation of the license to practice medicine, there will be no really reliable statistics. And this will only be brought about when the state health services throughout the land furnish a permanent career for life instead of being, as they are but too often at present, a side-line of politics-medical or otherwise. And these services should furnish a career like the federal civil service, to sanitary engineers and chemists as well as to physicians. The people must learn that their health is too valuable to entrust to temporary health officers or to physicians who devote to the discharge of their duties as health officers only such irregular moments as can be spared from private practice.-Carl L. Alsberg, Am. Jour. PuZ. Health. 